\title{
Memória, Cotidiano e Trabalho: notas sobre modos de vida e subjetividades na Serra do Açor, Portugal
}

\section{Memory, Daily Life and Work: notes on ways of life and subjectivities in the Serra do Açor, Portugal}

Rosemeire Aparecida Scopinho - Doutora em Sociologia, professora associada da Universidade Federal de São Carlos, Psicologia Social do Trabalho e Sociologia Rural. E-mail: scopinho@ufscar.br

Norma Felicidade Lopes da Silva Valencio - Doutora em Ciências Humanas, Programa de Pós-Graduação em Ciências da Engenharia Ambiental da Universidade de São Paulo São Carlos - SP, Sociologia dos Desastres. E-mail: normaf@terra.com.br

Luciano Fernandes Lourenço - Doutor em Geografia, professor associado com agregação da Universidade de Coimbra, Ciências da Terra e do Ambiente. E-mail: luciano@uc.pt

\section{Resumo}

$\mathrm{Na}$ região serrana de Açor (Portugal), o rural caracteriza-se pelas idas e vindas dos aldeões entre o campo e a cidade, em busca de trabalho e reprodução da vida social. Com base em observações etnográficas realizadas em oito aldeias localizadas no Distrito de Coimbra e apoiado nos conceitos de memória social, cotidiano e trabalho, o artigo propõe uma reflexão sobre as construções materiais e simbólicas que sustentam/enfraquecem os vínculos sociais que caracterizam o modo de vida aldeão.

\begin{abstract}
In the mountain region of Açor (Portugal), rural is characterized by the comings and goings of the villagers between the countryside and the city, in search of work and reproduction of social life. Based on ethnographic observations in eight villages located in the district of Coimbra and using the concepts of social memory, daily life and work, the article proposes a reflection on the material and symbolic constructions that sustain / weaken the social ties that characterize the way of life villager.
\end{abstract}

\section{Palavras-chave}

Memória Social, Trabalho, Cotidiano, Modo de Vida.

\section{Keywords}

Social Memory, Work, Daily Life, Way of Life. 


\section{INTRODUÇÃO}

Na região serrana de Açor (Portugal), o esvaziamento do rural, por êxodo e/ou envelhecimento populacional, é um fenômeno que se intensificou nas últimas décadas e se expressa na forma de mudanças na economia e nos modos de vida, antes baseados, fundamentalmente, na atividade agrossilvopastoril. Aldeias esvaziadas contribuem para agravar outro problema recorrente nesta região: a frequência e a gravidade com que acontecem os incêndios florestais, o que, por sua vez, mobiliza ainda mais os seus moradores na busca de melhores condições para trabalhar e viver nas cidades do entorno e/ ou nos grandes centros urbanos de Portugal e da Europa. No centro deste círculo vicioso, encontra-se a exploração madeireira e de resina, principal atividade econômica desta região, que envolve as pequenas e micropropriedades rurais, cujas recentes mudanças no tipo de espécie cultivada e no seu manejo têm contribuído para agravar o problema dos incêndios e o esvaziamento do mundo rural.

No entanto, esse esvaziamento não é de todo completo e apresenta algumas nuances diferenciadas. No verão português de 2013, realizamos uma pesquisa em oito aldeias do Distrito de Coimbra, com a finalidade de analisar a construção social dos desastres relacionados aos incêndios florestais na memória social de idosos, especialmente os processos que denotam a degradação da vida cotidiana e aqueles que exigem a adoção de novas estratégias, na esfera privada e pública, para revitalizá-la. No decorrer desta pesquisa, observamos que o manejo da floresta, na verdade, prescinde da presença humana constante, haja vista que os ciclos produtivos do pinheiro e do eucalipto são de trinta e dez anos, respectivamente, e o extrativismo da resina e da castanha é sazonal. A escassez de oferta de empregos regulares leva os aldeões a migrarem para trabalhar nas cidades do entorno. No entanto, muitos mantêm as suas casas para nelas passarem os finais de semana e as temporadas de verão; outros, depois de aposentados, voltam a ocupar as suas antigas casas e fazem da agropecuária mais um passatempo do que atividade econômica. Assim, no que se refere à ocorrência de incêndios, o rural não é tão densamente ocupado ao ponto de permitir que os aldeões mantenham-se vigilantes no controle desta problemática e nem tão vazio de modo que estes eventos não os afetem.

Mas o que motiva os aldeões no vai-e-vem constante entre a cidade e o campo? Baronet (2011), ao estudar o movimento migratório dos jovens no Concelho de Castro Daire, distrito de Viseu, com o aporte dos conceitos de dinâmicas boomerang e atração-repulsão ${ }^{1}$, explicou que esta estratégia migratória

1 Dinâmica boomerang diz respeito ao movimento migratório, mais ou menos regular, realizado em diferentes temporalidades que fazem os jovens entre o campo e a cidade, ao regressarem 
possibilita ao aldeão usufruir o melhor dos dois mundos. Nas cidades eles encontram possibilidades de fixação porque há empregos, redes sociais de apoio e de interconhecimento, maior diversidade social e cultural; no campo eles revivem a memória coletiva e familiar, o sentimento de pertença e desfrutam o contato com a natureza e a tranquilidade de uma vida mais simples. Em suma, para este autor, nas cidades os jovens encontram possibilidade de fixação e no campo as possibilidades são de vinculação.

As observações etnográficas realizadas nas aldeias do distrito de Coimbra corroboram as análises de Baronet (2011) e nos levaram a refletir, mais especificamente, sobre que construções materiais e simbólicas sustentam/ enfraquecem os vínculos sociais que caracterizam os modos de vida nas aldeias. Este é o propósito deste artigo. Especificamente, tratamos de caracterizar a convivência que se estabelece entre o modo de vida tradicional e o moderno nas aldeias pesquisadas, com ênfase nas atividades cotidianas de trabalho e de reprodução da vida social. A reflexão é balizada pelas seguintes questões: Como se configura a ruralidade nestes territórios? Que conjunto de características, relações e valores envolvem esta ruralidade?

Do ponto de vista metodológico, partimos do pressuposto de que os desencontros entre a memória oficial e aquela que se constrói por meio dos acontecimentos e relações que se estabelecem no tempo presente entre as personagens do lugar podem contribuir com a compreensão da riqueza subjacente à vida cotidiana (BOSI, 1979). As informações obtidas por meio das observações etnográficas permitiram apreender elementos importantes do modo de vida local, desde as formas de trabalho existentes, até aos costumes e tradições mantidas, passando pela organização dos diferentes espaços de vivência. No percurso analítico, elas foram complementadas e ilustradas com a produção discursiva dos moradores das aldeias, registradas formal ou informalmente por meio de entrevistas individuais e coletivas realizadas durante os trabalhos de campo. Assim foi possível confrontar discursos e práticas sociais.

Primeiramente, esboçamos um quadro teórico de referência para a reflexão, procurando articular os conceitos de vida cotidiana, modos de vida, memória social, representações sociais e trabalho. Na sequência, descrevemos o cenário em foco, com ênfase nas atividades produtivas, procurando discuti-lo à luz das questões levantadas e do referencial construído.

esporadicamente ao local de origem no campo sem lá permanecerem porque já estão fixados na cidade; a dinâmica atração-repulsão refere-se ao retorno à região de origem, movido pela força subjetiva dos laços familiares e comunitários, cuja permanência é de curto prazo porque, objetivamente, o campo não oferece condições de permanência (BARONET, 2011). 


\section{MODOS DE VIDA E SUBJETIVIDADES}

Se, para o homem comum, a vida cotidiana apresenta-se como uma espécie de território, onde as relações sociais ganham colorido e indicam as possibilidades de realização do sujeito, também é nela que as limitações concretas e simbólicas desta realização se manifestam (MARTINS, 1998). Possibilidades, por um lado, e limitações, por outro são, respectivamente, vias abertas e obstruídas pelas regras de tráfego da sociabilidade daqueles que convivem, produzem e partilham um senso comum. Trata-se de um conhecimento fundamental acerca do mundo vivido, reelaborado continuamente, e cujos significados, dinamicamente produzidos, são validados na interação social (MARTINS, 1998; 2000), onde se materializam na forma de um lugar identitariamente referenciado (ZHOURI; OLIVEIRA, 2010).

A memória social é o elemento ativo que dá sentido às feições do lugar, dota a sociabilidade miúda do dia a dia de uma história mais densa e, enfim, manifesta a energia pulsante do senso comum. Constituindo camadas de variadas experiências e conhecimentos, tanto pessoais como coletivos, testados nas contingências e entremeados nas rotinas, compartilhados pelo discurso e pelas práticas adotadas, as quais são alvo de contínuos reexames, ruminações e emoções que suscitam novas reassociações e significados sobre o mundo e o sujeito no mundo, a memória social vincula assim o visível e o invisível da vida cotidiana de um lugar. O esforço coletivo que, porventura, o grupo social que enfrenta determinadas adversidades faça para elaborar interpretações aceitáveis, no âmbito do seu próprio meio social, sobre aquilo que foi vivido coletivamente como uma experiência incomum de mudança radical ou mesmo ameaça à sua sobrevivência e que, depois, engendra a adoção de novos mecanismos de autoproteção, tem muitos pilares. Memória social é, pois, um importante recurso conceitual, que propicia a compreensão de tais pilares, uma vez que, conforme referem Haas e Jodelet (2007), ela é um espaço social e intersubjetivo que, compartilhado por meio de diferentes linguagens, pode ser entendido como uma arena onde diferentes grupos sociais lutam pela sobrevivência material e simbólica.

Para que assim seja, a memória social não pode ser concebida como mero resgate do passado, mas sim como um instrumento de busca pela valorização e legitimação da pertença social, instrumento este que confere poder aos sujeitos na luta cotidiana pela manutenção da vida e pela reconstrução psicossocial diante dos eventos que se apresentem no cotidiano. Assim, ela não se constrói do nada, mas das relações que os sujeitos estabelecem entre si e com as estruturas sociais. Memória é, então, trabalho, no dizer de Bosi (1979), que se realiza por meio desse conjunto de interações e está, cultural e ideologicamente, vinculada a determinados grupos sociais e aos conflitos subjacentes às suas trajetórias. 
Portanto, o seu sentido está inscrito não somente nas estruturas cognitivas de quem lembra, mas também no conjunto de códigos, valores e normas que informam determinada estrutura social e os sujeitos que delas participam. A nitidez do seu conteúdo não se relaciona apenas ao sujeito que recorda, mas à experiência social do seu grupo de referência, do mesmo modo que o conteúdo das lembranças, por sua vez, relaciona-se com os interesses sociais que com elas estão relacionados.

É assim que memória (passado) e vida cotidiana (presente) andam juntas no processo de construção de sentidos que os sujeitos conferem ao mundo e às suas condições de vida. A noção de condiçôes de vida refere-se à reprodução social no sentido objetivo, como possibilidade de acesso por meio do trabalho aos bens de consumo coletivo, e subjetivo, como possibilidade de pertença e controle das relações sociais e políticas dentro e fora do trabalho (LOBO, 1992). A noção de modo de vida é fundamental para entender como as condições objetivas do real são vivenciadas pelos sujeitos, porque ela remete aos valores, tradições e códigos morais presentes nos seus universos simbólicos (TELLES, 1992).

Os sujeitos constroem e partilham sentidos sobre a realidade vivida não apenas com a finalidade de interpretá-la, mas também de transformá-la. Tais sentidos expressam as suas identidades sociais e culturais, mas não são abstrações puras porque tanto são gerados quanto se integram às suas experiências e práticas cotidianas, refletindo e constituindo reflexos da estrutura social, da ideologia e da cultura que as sustentam. A relação é de mão dupla e mediada pela atividade do sujeito no mundo, ou seja, o trabalho que ele realiza para produzir e reproduzir a vida.

Richard Sennett, ao discutir as relações entre o fazer e o pensar, defende que "[...] o processo de feitura das coisas concretas revela a nosso respeito." (SENNET'T, 2009, p.18). Para este autor, a atividade material é mediadora dos sentimentos e do pensamento no trabalho humano, mesmo em condições adversas. É falsa a divisão entre quem pensa e quem faz - que o autor considera um artefato cultural do capitalismo - porque "[...] sentimento e pensamento estão contidos no processo do fazer." (p.17) "Materialmente, os seres humanos são hábeis criadores de um lugar para si mesmos no mundo" (p. 24). Então, para este autor, um trabalho bem feito, de acordo com as nossas habilidades criadoras, é o que nos motiva para trabalhar sempre, mais e melhor.

Sennett (2009) chama de artifice aquele trabalhador que se dedica à arte pela arte, que está engajado em uma atividade prática, mas, não necessariamente, faz dela um meio para alcançar um fim. Ele desenvolve a sua habilidade artesanal em alto grau e recebe recompensas emocionais por isto, tais como o vínculo com a realidade tangível e o orgulho de seu trabalho. "Habilidade artesanal designa um 
impulso humano básico e permanente, o desejo pelo trabalho bem feito por si mesmo" (SENNET, 2009, p. 19), que vai além da habilidade manual, mas está centrada na coisa produzida em si mesma. $\mathrm{O}$ artífice encontra e resolve problemas, contorna os desafios que se interpõem no processo de trabalhar, sustentando um diálogo entre a mão, a cabeça e os materiais utilizados que não pode ser auferido e mapeado por instrumentais porque se trata de um conhecimento tácito, que nem sempre pode ser transformado em números ou palavras. A intimidade com os materiais utilizados desenvolve uma espécie de consciência material.

Como criador de si mesmo, o artífice realiza-se por meio de um trabalho bem feito, que tanto é o seu instrumento de criação quanto o que garante a sua habilidade. A motivação para fazer bem feito é mais importante do que o talento, quando se trata de desenvolver habilidades artesanais e duas condições são importantes: o aprendizado lento (diálogo consigo mesmo e com os materiais - o estudo) e o hábito (repetição). É assim que o fazer e o pensar andam juntos e são impulsionados pelo desejo de fazer bem feito. Para isto, o ritmo da rotina do artífice deve ser livre (como num jogo ou numa brincadeira infantil) e é preciso que haja tempo para estudar e organizar a repetição e o treino, de modo que o seu conteúdo seja modificado. São marcas distintivas da atividade artesanal a capacidade de tolerar a desorganização e a incerteza e também o grande envolvimento em atividades repetitivas que fazem aprimorar a técnica "[...] a experiência de estudar a própria prática e modulá-la de dentro para fora" (SENNET, 2009, p. 49). O artífice somente se autorrealiza se tiver tempos e movimentos livres para articular práticas concretas e ideias, testando e repetindo técnicas até que o produto material desta articulação possa satisfazer o seu próprio padrão de excelência.

Richard Sennett deixa claro que, embora a figura do artesão medieval seja o protótipo do artífice, este não é um tipo de trabalhador que só existiu em um passado longínquo e é possível encontrá-los nos tempos atuais, independentemente do tipo de atividade, porque se trata de uma característica subjetivamente desenvolvida. $\mathrm{Ou}$ seja, o artífice não é produto de um determinado modelo de organização e gestão do trabalho e é possível ser artífice em qualquer tempo histórico, desde que as condições acima mencionadas estejam presentes. "Com certeza é possível se virar na vida sem dedicação. O artífice representa uma condição humana especial: a do engajamento." (SENNET, 2009, p. 30, grifos do autor).

Embora se valha de muitos exemplos para discutir as relações entre o fazer e o pensar: o carpinteiro ameaçado por uma fábrica de móveis que se instalou na vizinhança, a técnica de laboratório que poderia transferir o problema encontrado para o chefe, o maestro que excedeu o tempo de uso da sala de 
ensaio para melhorar a apresentação, o trabalhador do sistema operacional Linux que o aperfeiçoa voluntariamente, Sennett (2009) tem sido criticado por deixar de lado os contextos sociais e institucionais que se colocam entre o trabalho e os trabalhadores nos tempos atuais. No nosso entendimento, se "o artífice representa uma condição humana especial", ele pode ser encontrado nas aldeias do distrito de Coimbra. É isto que procuraremos mostrar na sequência.

\section{TRABALHO, TRADIÇÕES E VALORES NAS ALDEIAS SERRANAS}

As aldeias, pertencentes ao alto distrito de Coimbra, equivalem à ideia de lugar, isto é, a um processo social de territorialização, com forte vinculação identitária e moldado por um tempo histórico consideravelmente longo, uma vez que, muitas delas, remontam a várias centenas de anos. Coimbra é distrito, que possui vários concelhos (municípios), compostos por freguesias (vilas e aldeias) e estas por lugares (aldeias).

Incrustadas na Serra do Açor, as freguesias são, geralmente, cortadas por estreitas estradas em curvas que as interligam e por onde passam todos os veículos, desde os pequenos carros de passeio até os grandes caminhões de transporte de madeiras, que causam transtornos, visto que a estrada é, geralmente, também a rua principal na qual os moradores locais se encontram e sociabilizam e está ladeada pelas residências e pontos comerciais. O tamanho e o excesso de carga dos caminhões provocam ruídos que abalam o silêncio característico do lugar e os fazem circular com dificuldades, danificando o calçamento e, por vezes, arrebentando os cabos de internet. A arquitetura compõe mosaicos de construções antigas, mas recém-reformadas, rodeadas por pequenos pomares e jardins em flor, que coexistem com as casas que foram abandonadas pelos migrantes, muitas em estágio avançado de ruínas. A diversidade de estados de conservação do mosaico arquitetônico é prova inequívoca do movimento de idas e vindas da população aldeã.

A migração em busca de melhores condições de trabalho e vida parece ser uma constante na vida dos aldeões, intensificada na segunda metade do século passado com a industrialização do país. A reconstrução das rotas traçadas por alguns moradores mostra que a migração aconteceu, geralmente, entre os 16 e 25 anos de idade, embora houvesse quem tenha migrado ainda mais precocemente para trabalhar. As suas trajetórias de trabalho revelam a inserção em atividades que não exigem elevado grau de qualificação, exercidas no setor de comércio e de prestação de serviços, no âmbito público ou privado, especialmente nos ramos de serviços domésticos, transporte, hospedagem e alimentação. 
Entre os homens, o motivo da migração foi, predominantemente, a busca de trabalho e renda que permitisse viver melhor ao voltar para a aldeia de origem; as mulheres migraram também para acompanhar os maridos após o casamento. Lisboa foi o destino mais citado, mas a rota migratória dos habitantes da Serra do Açor também inclui as aldeias do entorno, especialmente quando se trata de migração por causa de matrimônio, a cidade de Coimbra e países como a França, a Suíça, a Espanha, a Bélgica, os países africanos colonizados por Portugal, especialmente Moçambique, entre outros.

A migração é naturalizada e representada como uma tendência inexorável: "Saíram porque chegou a altura da vida deles que tinham que sair" (moradora da Aldeia de Chão Sobral). Os filhos herdam não somente os meios de produção e as habilidades profissionais dos pais, mas também a sina de terem que deixar a propriedade em busca de trabalho em certa altura da vida. A família ou parte dela se vai, mas ficam as propriedades para onde os aldeões sempre retornam para passar os finais de semana, feriados e férias e, depois de aposentados, quem sabe retornar definitivamente se a condição de saúde permitir. Por isto mesmo, o número de famílias permanentes e temporárias em cada aldeia é variável, por exemplo: 11 e 50 famílias em Gramaça e 100 e 30 famílias em Chão Sobral, respectivamente, segundo o relato dos seus moradores.

A estrutura fundiária das aldeias é composta de pequenas e micropropriedades, muitas não alcançam mais de uns metros quadrados. As propriedades permanecem por décadas com as mesmas famílias que podem possuir vários pequenos pedaços de terra, não necessariamente contíguos, resultados de diferentes heranças ou modos característicos de reparti-las, a exemplo de um aposentado cujos vários pedaços somavam $1500 \mathrm{~m}^{2}$ e estão espalhados pela aldeia. "Um bocadinho aqui, um bocadinho lá. Assim, que nem dá para medir." (morador da Aldeia Gramaça)

O trabalho nas aldeias é marcado por tempos muito distintos: os tempos físicos, dados pelas estações do ano, e os tempos sociais da vida dos aldeões, que definem os movimentos migratórios. No verão, quente e seco, o trabalho na agricultura começa ao sol nascer, às cinco horas, e estende-se até às dez horas da manhã, quando o calor já se torna insuportável. Deste horário até às 17 horas, eles preparam e fazem as refeições, cuidam da casa, descansam ou trabalham em outros lugares. Às 17 horas, retornam para as terras para cuidar dos animais, regar as plantas, continuar o que o sol forte interrompeu. No verão, as aldeias ganham vida, as casas fechadas recebem os moradores temporários e acontecem as festas familiares e comunitárias. No inverno, umedecido pelas chuvas e pela neve, as condições climáticas nem sempre permitem o plantio; os dias são mais 
curtos e dedicados aos cuidados com os animais. Nas aldeias esvaziadas ficam somente os moradores permanentes.

Os jovens interrompem as rotinas marcadas pelas estações do ano ao saírem das aldeias para estudar. Do primeiro até o décimo segundo ano, a escolarização é obrigatória. Do primeiro ao nono ano, os estudantes são levados todos os dias para as grandes escolas que atendem as várias aldeias de cada concelho. Os três últimos anos são cursados nas sedes dos concelhos, com transporte para ir e vir. Para cursar a universidade, os jovens saem de casa e nem sempre voltam depois de formados porque as aldeias oferecem poucas oportunidades de emprego. É neste tempo da vida que se inicia a relação com as cidades, o vaie-vem que, em geral, só termina com a aposentadoria. Nas aldeias, os empregos são gerados, principalmente, pelos serviços públicos: a administração municipal e das freguesias, escolas e creches, lar de idosos e postos de saúde. Muitos trabalhadores viajam todos os dias para trabalharem na sede do concelho ou em aldeias próximas.

Os aposentados dedicam-se à pequena agricultura, desenvolvida nas hortas e pomares, e aos cuidados com os animais. Os que trabalham nas aldeias ou cidades do entorno também se dedicam aos cuidados com as hortas, pomares e pequenos animais e o fazem antes e depois da jornada de trabalho. Os que trabalham em cidades mais distantes cuidam das suas propriedades nos finais de semana e nas férias.

Em resumo, a população economicamente ativa tem uma dupla vida de trabalho, na cidade e no campo, mas isto não significa desgaste ou um fardo a carregar. Pelo contrário, porque o trabalho na cidade representa a realização profissional, a garantia de sustento e de proteção social na velhice, ou seja, é o que alimenta materialmente o aldeão; o trabalho no campo representa a manutenção e o estreitamento de vínculos com a aldeia e com os conterrâneos, a atualização de tradições seculares, o prazer de trabalhar para si e por si. É este o trabalho que alimenta, subjetivamente, o aldeão, que lhe confere "uma condição humana especial", como refere Sennett (2009). É este o trabalho que articula a vida cotidiana, realidade tangível, à memória social dos habitantes do lugar e realiza, subjetivamente, o aldeão.

Para compreender que construções materiais e simbólicas sustentam/ enfraquecem os vínculos sociais que caracterizam os modos de vida nas aldeias, convém mostrar, primeiramente, que trabalho é este para depois tentar compreender por que é este trabalho.

As atividades produtivas predominantes são diversificadas e desenvolvidas de modo integrado. Na pecuária, eles ocupam-se da criação de pequenos animais, tais 
como cabras, ovelhas, coelhos e frangos, que utilizam como ração o milho produzido nos socalcos ${ }^{2}$ e como cama o mato que cresce entre os pinheiros. A agricultura é realizada nos socalcos e quintais onde se planta milho, batata, feijão, centeio, grão-de-bico, pimentão, alface, couve, repolho, mostarda, uva, tomate, espinafre, temperos, morango, kiwi, cítricos, ginja, oliveiras, entre outros. Em cada quintal e ao longo das ruelas nas aldeias, encontra-se também uma grande variedade de frutas: cerejas, peras, nozes, castanhas portuguesas, entre outras. Em cada pedaço de terra plantada há uma grande variedade de espécies, um mosaico de cores e texturas diferentes, incluindo flores de vários tipos (rosas, palmas, petúnias, hortênsias, cravos, dálias, cactos, suculentas, camélias). As videiras funcionam como cercas vivas ou coberturas de garagens e outras estruturas. São utilizados adubos orgânicos e também químicos, assim como defensivos contra algumas pragas, especialmente nas videiras e críticos. As famílias organizam bancos de sementes para as hortaliças e temperos; as de batata e grãos são compradas. A base técnica é, no geral, muito tradicional e rudimentar (basicamente composta de enxadas e outros instrumentos de poda e colheita manual) porque as áreas de cultivo são muito pequenas, os terrenos são íngremes e os socalcos só permitem a entrada de pequenos tratores (que substituíram os bois), roçadeiras e cortadores de grama. A água é abundante, vinda de fontes naturais, e armazenada e repartida entre a comunidade.

Em geral, a agropecuária é, tipicamente, de subsistência e os poucos excedentes não são comercializados, mas distribuídos entre os familiares e vizinhos. É desenvolvida mais como passatempo, alimento subjetivo, do que por necessidade, embora também signifique parte do orçamento doméstico porque acaba complementando a renda familiar que, geralmente, é composta de salários e aposentadorias. Parte da produção é processada nas agroindústrias artesanais de queijos, de azeite de olivas e de vinho de uvas, para consumo próprio.

As pessoas herdam também pequenas fábricas, geralmente, de azeite (lagar), vinícolas, entre outras, empreendimentos estritamente familiares, algumas cujas aparências lembram as corporações de ofícios descritas na Idade Média. O processamento do azeite de olivas é realizado nos lagares, porque depende de equipamento para prensar as olivas e extrair o azeite. O proprietário das olivas paga pelo serviço prestado, que ainda é feito nas aldeias em pequena escala. Em grande escala, a extração do azeite de olivas é realizada de modo mecanizado e informatizado. Visitamos um lagar antigo em Coja, que agora se tornou um restaurante turístico. O prédio ainda conserva os antigos equipamentos. Grandes engrenagens de ferro movidas por roda d'água acionavam as prensas de pedra

2 Tecnologia desenvolvida há séculos que consiste na realização de cortes planos em terrenos de acentuado declive, sustentados por uma espécie de muro de pedras que serve de arrimo. 
que amassavam as frutas. $O$ vinho ainda é feito artesanalmente por algumas famílias. Artesanalmente quer dizer “(...) amassar as uvas com os pés, deixar ferver e engarrafar (...)" (moradora da Aldeia das Dez). Trata-se de um vinho suave, quase um suco de uvas. Outras bebidas também são produzidas de modo caseiro: licores de várias frutas, desde castanha até amora, pêssego, ginja e outras. Da ginja também se faz a ginjinha, espécie de licor mais espesso em que as frutas permanecem curtindo nas garrafas; a sopa é outro tipo de licor, se bem que mais forte, em que se utilizam um ou mais tipos de frutas secas curtidas em álcool; para fabricar a jeropiga, utilizam-se duas partes do vinho de uva não fermentado e uma de aguardente.

A atividade industrial é quase inexistente. Encontramos uma fábrica de facas na Aldeia de Chão Sobral, cuja proprietária herdou do pai que trabalhava na construção de estradas e fazia facas em casa para complementar a renda. Em certa altura da vida, ele ampliou a oficina e contratou empregados e hoje a fábrica é a principal fonte de renda do casal herdeiro e seus nove filhos (entre 9 e 28 anos de idade). Está instalada do outro lado da rua, quase em frente à residência da família, em um cômodo de, aproximadamente, $5 \mathrm{~m}^{2}$, onde estão dispostas as máquinas, ferramentas, matérias primas, estoques e tantas outras coisas. Grande parte das máquinas foi inventada e fabricada pelo próprio fundador. Há 15 anos, a família comprou uma ou outra pequena máquina com recursos oriundos de projetos financiados pela, então, Comunidade Econômica Europeia (hoje União Europeia). Se comparada com outros modelos de instalação fabril, a organização do espaço é caótica, mas ali acontece o processo produtivo de pequenas facas e, às vezes, outros utensílios como tenazes, sempre por encomenda. O processo de fabricação é simples e os equipamentos são operados ora pelo marido, ora pela esposa. A chapa de metal é talhada e as bainhas são temperadas no pequeno forno; posteriormente, são lixadas e polidas, quando ficam prontas para receber o cabo, que é feito ali mesmo com madeira da região e é fixado com rebites. A fábrica pode produzir até 10 dúzias de facas por dia. A proximidade da residência e da fábrica permite o livre trânsito da família entre esses espaços, onde o trabalho se fizer necessário: ora na produção de facas, ora nos serviços domésticos, ora no cuidado da horta e dos animais.

No conjunto, a exploração florestal - corte da madeira, extração de resina (no caso do pinheiro) e de castanhas - é uma atividade econômica importante na região e no país. No entanto, as manchas de florestas estão espalhadas numa estrutura fundiária composta por micropropriedades e nem sempre são exploradas ou são, predominantemente, exploradas em regime associativo (COELHO, 2003). 
Coexistem com as atividades agropecuárias, extrativistas e agroindustriais as da construção civil, do comércio e as relacionadas ao turismo, acompanhando as atuais tendências globais. Os pequenos estabelecimentos comerciais funcionam como lojas de conveniência, onde é possível encontrar desde gêneros alimentícios in natura e processados assim como uma grande variedade de utensílios de uso doméstico, produtos de higiene pessoal e objetos de decoração, pequenas ferramentas, presentes, entre outros itens fundamentais para a sobrevivência cotidiana. Demais transações comerciais são feitas nas cidades sedes dos concelhos, onde o comércio e os serviços são mais diversificados e especializados (combustível, máquinas e implementos, serviços médicos e hospitalares, bancários, por exemplo).

Por que este trabalho? $\mathrm{O}$ modo como se realizam as atividades produtivas nas aldeias somente é possível porque se trata de produção de pequena escala, desenvolvidas pelas próprias famílias que herdaram dos antepassados os meios de trabalho, as habilidades profissionais e certos valores que sustentam as tradições do povo do lugar, principalmente, pelo valor que tem o trabalho caprichoso na vida das pessoas. Associados a este valor, que do ponto de vista da nossa reflexão tomamos como o principal, estão ainda outros, tais como a partilha, o mutualismo, o respeito ao bem comum, a honestidade, a integridade, a religiosidade, que fazem valer mais as palavras empenhadas do que os contratos firmados.

A agricultura é um perfeito exemplo do que hoje chamamos de agroecologia: cultivo diversificado e integrado com a pecuária, consorciamento de culturas, práticas conservacionistas de recursos naturais. Vista do alto das Serras, a paisagem das aldeias já revela uma das mais antigas práticas agrícolas ali desenvolvidas: o cultivo nos socalcos que, de modo inteligente, disponibiliza solo plano para a agricultura e facilita o trabalho do agricultor ao mesmo tempo em que combate as erosões pluviais. A distribuição de recursos hídricos também é feita de acordo com esquemas criados e acordados na comunidade há décadas. Em pontos estratégicos,encontram-se tanques (de alvenaria ou não) que são fechados para se encherem com as águas da bica e utilizados na irrigação das hortas. Pelas aldeias, há pequenos canais (chamados de levadas) por onde a água escorre favorecida pela declividade do terreno. O canal passa pelos terrenos e em cada um deles há uma entrada que permanece fechada com pedras e panos ate que chegue a vez do seu proprietário utilizar a água durante certo tempo, que é sempre proporcional ao tamanho do seu terreno. Depois de aberta a passagem, dentro do terreno, a água escorre pelas leiras, estreitos canais de irrigação existentes entre os canteiros. Cada qual vai abrindo e fechando o sistema, que permanece irrigando pelo tempo que lhe é destinado (em horas ou quartos de hora). 
Não há fiscalização ou qualquer mecanismo de controle do uso. O que há é o respeito da comunidade pelo que fui combinado e não foi referida a existência de conflitos relacionados ao uso deste sistema de distribuição de água. Quando se pergunta sobre como e quem decide, por exemplo, sobre o tempo de irrigação destinado a cada terreno, resposta é direta e simples: "[...] sempre foi assim e nós continuamos [...]" "[...] sempre? Desde quando? [...]" "[...] há mais de quarenta anos [...]" (moradora da Aldeia Piódão). 40 anos pode não ser o tempo de existência do sistema, que pode ser bem mais antigo, mas o tempo que a pessoa entrevistada conhece as regras de funcionamento deste. Este é um exemplo de prática comunitária de partilha de recursos e respeito pelo alheio que o respeito à tradição não deixa questionar e modificar.

A partilha do que se produz entre parentes, vizinhos e amigos é outra tradição exemplar e a nossa estada na Aldeia das Dez testemunhou, cotidianamente, esta prática. "Melhor dar do que estragar", disse uma moradora. A solidariedade também se manifesta no cuidado e na vigilância da saúde dos idosos, principalmente os solitários, parcela significativa da população das aldeias. "Os vizinhos são a família" (moradora da Aldeia Rio de Mel).

Observa-se certo padrão de igualdade social entre os moradores da serra, que se manifesta em várias dimensões da vida. Desde a propriedade de pequenas parcelas de terra e de moradia até, dependendo da faixa etária, certa homogeneidade no grau de escolarização, até as formas de cultivo, a base técnica utilizada, os produtos cultivados, o padrão de vida Esta igualdade aparente pode estar na base das relações de respeito observáveis nas comunidades. Se há igualdade, não há necessidade de competir ou subtrair nada de ninguém. Os relatos descreveram uma situação de autoproteção e confiança mútua entre os vizinhos que, assim, podem sair de suas casas deixando a porta encostada, frutas e hortaliças permanecem nas quintas e não são levadas, os carros ficam estacionados nas ruas e não são roubados, entre outros exemplos. Respeita-se o que é do outro porque se tem o mesmo.

Em suma, nas aldeias serranas, as tradições mantidas podem ser percebidas nas práticas de trabalho, nas relações sociais, nos festejos religiosos que celebram anualmente os padroeiros da cada aldeia, no luto permanente das viúvas que permanecem vestidas de preto pelo resto da vida e não se casam novamente. Mas a modernidade também deixa ali os seus rastros percebidos, por exemplo, pelas transformações em curso na exploração florestal, pelo avanço do turismo que transforma quintas tradicionais em hotéis de luxo e faz crescer o volume de carros que cortam as estradas, pelo tilintar dos telefones celulares cada vez mais sofisticados, pela proliferação das antenas de televisão a cabo, pelas menções 
ao Facebook e a outras trocas eletrônicas. Esses são os indícios de um cotidiano que também está conectado com o mundo globalizado e denunciam as fissuras existentes na aparente homogeneidade dos modos de vida serranos.

\section{REFERÊNCIAS}

BARONET, P. R. O campo já não é só campo e a cidade também se transforma: como ler a relação entre o campo e a cidade no contexto migratório. Lisboa, ISCTE, 2011. Disponível em http://www.conferencias.cies.iscte.pt/index.php/icyurb/ sicyurb/paper/viewFile/147/60. Acesso em 12/05/14.

BOSI, E. Memória e sociedade: lembrança de velhos. T.A. Queiroz Editor Ltda: São Paulo, 1979.

COELHO, R. S. Arborisae as vossas terras: um estudo sobre o valor das florestas portuguesas. Porto: Faculdade de Economia do Porto, 2003. Disponível em http:// www.fep.up.pt/disciplinas/LEC514/trabalhos/arborisae\%20as\%20vossas\%20terras. pdf. Acesso em 17/05/2014.

HAAS, V.; JODELET, D. Pensée et mémoire sociales. In: Pétard, J. P. (Ed.). Psychologie Sociale. Paris:Bréal, 2007. p. 111-160.

LOBO, E. S. Caminhos da Sociologia no Brasil: modos de vida e experiência. Tempo Social, Rev. de Sociologia da USP, v.4, n.1-2, p.7-15, 1992.

MARTINS, J. de S. O senso comum e a vida quotidiana. Tempo Social, Rev. de Sociologia da USP, v. 10, n. 1, p. 1-8, 1998.

A sociabilidade do homem simples: quotidiano e história na modernidade anômala. São Paulo: Editora Hucitec, 2000.

SENNETT, R. O artífice. Rio de Janeiro, São Paulo: Editora Record, 2009.

TELLES, V. S. A experiência da insegurança: trabalho e família nas classes trabalhadoras urbanas em São Paulo. Tempo Social, Rev. de Sociologia da USP, v.4, n.1-2, p. 53-93, 1992.

ZHOURI, A.; OLIVEIRA, R. Quando o lugar resiste ao espaço: colonialidade, modernidade e processos de territorialização. In: ZHOURI, A.; LASCHEFSKI, K. (Orgs.). Desenvolvimento e conflitos ambientais. Belo Horizonte: Editora da UFMG, 2010. p. 439-462. 